\title{
Skull Base Hemangiopericytoma: Treatment Options
}

\author{
Mathew B. Kiberd, Robert James Macaulay, Sean D. Christie
}

Hemangiopericytoma is a locally recurrent, highly vascularized neoplasm that originates from pericytes, pericapillary spindle-shaped cells. ${ }^{1-7}$ These cells are related to smooth muscle cells but have no contractile capability. 5,6 Hemangiopericytomas are rare, accounting for fewer than $1 \%$ of intracranial tumors, and are indistinguishable radiographically from meningiomas. ${ }^{8,9}$ Definitive diagnosis must be made on histological findings. ${ }^{5}$ Distinction of this neoplasm from meningioma is critical because of the aggressive nature of the tumor; recurrence ranges from $32-56 \%$ although five year survival is good at 78-93\%.5,10,11 Local recurrence after complete resection can be delayed and accompanied by distant extraneural metastasis.

To our knowledge this is the first reported case of hemangiopericytoma at the skull base in the ventral foramen magnum. We discuss the patient's presentation and treatment options.

\section{Presentation}

The patient was a 34-year-old male presenting with severe neck pain and weakness suggestive of right $\mathrm{C} 8$ radiculopathy. $\mathrm{He}$ underwent an electromyogram (EMG) performed by a neurologist, which was unremarkable other than decreased conduction in the right peroneal nerve. Routine blood work and viral screening was negative, and no specific diagnosis or therapy was suggested. Two months after his initial EMG he sustained a traumatic work-related accident. A pipe hit the left side of his head and shoulder, throwing his head hard to the right. Weakness and stiffness on his left side became progressively worse. He was referred back to neurology, and underwent a detailed physical examination (Table).

His past history was significant for a motor vehicle collision at age ten resulting in a head and lumbar spine injury of uncertain nature and severity. He was a smoker with a family history of cancer and ischemic heart disease.

The suggested clinical diagnosis was cervical myleopathy from a central disc protrusion; however, an MRI (Figure 1A \& 1B) revealed an enhancing $2.9 \mathrm{~cm}$ ovoid tumor in the ventral foramen magnum exerting a mass effect, displacing the spinal cord posteriorly. The patient was referred to neurosurgery. The physical findings at that time (Table) demonstrate clinical progression of neurologic impairment.

\section{SURGERY}

A transoral approach was chosen to reduce the risk of cranial neuropathy or vascular insult. The options were discussed with

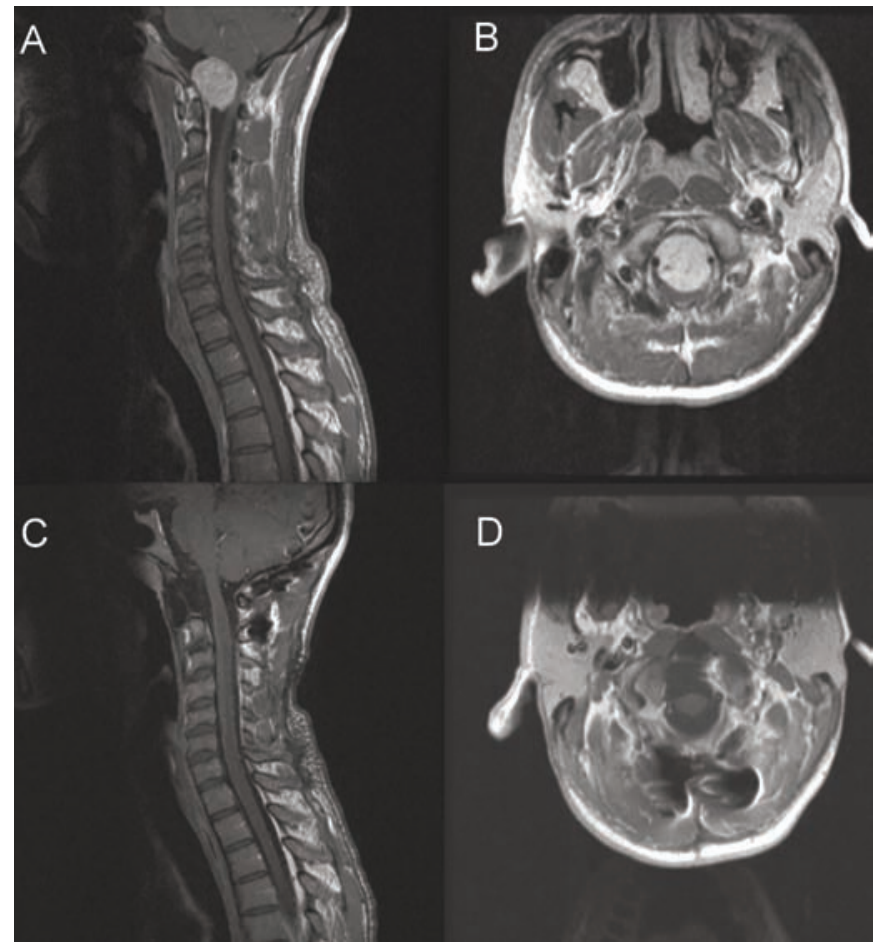

Figure 1: (A) T1 weighted MRI, sagittal section, post gadolinium preoperative image. (B) T1 weighted MRI, post gadolinium, axial section, preoperative image. $A+B$ show $2.9 \mathrm{~cm}$ enhancing ovoid lesion at the foramen magnum exerting a mass effect, displacing the spinal cord to the posterior. Vertebral arteries run laterally and are draped over the mass. (C) T1 weighted MRI, sagittal section, two years post operative image. (D) T1 weighted MRI, post gadolinium, axial section, two years post surgery, image. $C+D$ show total resection of lesion and relieved pressure of spinal cord.

From the School of Medicine (MBK), Department of Surgery Division of Neurosurgery (RJM, SDC), Department of Pathology (RJM), Dalhousie University, Halifax, Nova Scotia, Canada.

Received April 3, 2009. Final Revisions Submitted July 17, 2009. Correspondence to: Sean D. Christie, 3808-1796 Summer Street, Halifax, Nova Scotia, B3H 3A7, Canada. 
Table: Physical exam findings from three separate visits

\begin{tabular}{l|l|l|l}
\hline & Day 70 post EMG & Day 90 post EMG & One-year post surgery \\
\hline $\begin{array}{l}\text { Patient } \\
\text { complaint }\end{array}$ & $\begin{array}{l}\text {-Decreased function of left arm } \\
\text { and leg } \\
\text {-Unable to run } \\
\text {-Urinary hesitancy and sexual } \\
\text { dysfunction } \\
\text {-constant neck pain }\end{array}$ & $\begin{array}{l}\text {-left hand unresponsive } \\
\text {-muscle wasting on left arm } \\
\text {-hypersensitivity to cold } \\
\text {-numbness in neck area } \\
\text {-loss of sleep }\end{array}$ & $\begin{array}{l}\text {-Full function in all limbs } \\
\text {-Returned to full duties at } \\
\text { work }\end{array}$ \\
\hline $\begin{array}{l}\text { Physical } \\
\text { Exam }\end{array}$ & & & \\
\hline $\begin{array}{l}\text { Cranial } \\
\text { nerves }\end{array}$ & Intact & $\begin{array}{l}\text { Intact except IX diminished trapezius } \\
\text { and sternocleidomastoid strength }\end{array}$ & Intact \\
\hline Motor & $\begin{array}{l}\text { Spastic weakness left side of arm } \\
\text { and leg }\end{array}$ & Extensors 3/5 flexors 4/5 & 5/5 throughout \\
\hline Sensory & diminished pinprick on right side & $\begin{array}{l}\text { diminished pinprick on right and C-3, } \\
\text { 4 distribution }\end{array}$ & Sensation intact \\
\hline Reflexes & Pathological briskness on left side & no change & $\begin{array}{l}2 / 4 \text { throughout except } 3 / 4 \text { in } \\
\text { biceps and triceps }\end{array}$ \\
\hline Other & $\begin{array}{l}\text {-Spastic left foot gait } \\
\text {-Left foot Positive Babinski } \\
\text {-Poor coordination on } \\
\text { finger/nose heel/shin test } \\
\text {-Clonus in both ankles }\end{array}$ & $\begin{array}{l}\text {-Bilaterally positive Babinski } \\
\text {-Positive Hoffman } \\
\text {-Positive Romberg } \\
\text {-Clonus in both ankles }\end{array}$ & $\begin{array}{l}- \text { Normal tone } \\
\text {-Negative Hoffman } \\
\text {-Negative Romberg } \\
\text {-no clonus }\end{array}$ \\
\hline
\end{tabular}

the patient and he agreed to the procedure including a staged occipitocervical fusion for stability. ${ }^{12}$

Under satisfactory general anaesthesia, a fascia lata graft was harvested from the right leg. The patient was then rolled into the lateral position and a lumbar drain was placed.

The patient's head was then secured to the bed using a Mayfield headrest. To gain adequate exposure the palate was split just to the left of the uvula and stopping approximately 4 $\mathrm{mm}$ from the hard palate. Silk stay sutures were used to hold the incision open. The pharyngeal muscles were split in the midline and the base of the odontoid, the anterior arch of $\mathrm{C} 1$, the upper portion of the body of $\mathrm{C} 2$ and the clivus were identified and removed using a Kerrison rongeur and a high-speed burr. The cruciate ligament was identified and removed revealing the dura. Upon opening the dura, in a vertical fashion, the tumor was immediately visualized. The tumor was internally decompressed and packed to control the bleeding. The tumor edges were then reflected away from the vertebral arteries, lower cranial nerves and brainstem until the last of the mass could be delivered. A 1 $\mathrm{cm}$ margin of dura was then resected around the ventral tumor attachment and the residual dural edge was cauterized. The dural closure was performed in multiple layers utilizing Durepair ${ }^{\circledR}$ (Medtronic Neurosurgery; Goleta, CA), fascia lata autograft and Tisseel ${ }^{\circledR}$ (Baxter; Glendale, CA). The pharyngeal muscles were then closed in layers and the soft palate reapproximated. A nasogastric tube was placed, and the patient was sent to the intensive care unit wearing a rigid collar. He was subsequently brought back to the OR for posterior instrumented arthrodesis and iliac crest autografting.
An immediate postoperative MRI demonstrated complete resection of the lesion (not shown).

\section{Pathology}

The tumor was highly cellular (Figure 2) with a spindle cell/storiform pattern and rich vascularity, occasionally in a staghorn configuration. Mitoses were common and necrosis was present. Pericellular reticulin was demonstrable. CD34 and Bcl2 were positive by immunostaining, while epithelial membrane antigen (EMA) was negative. There was minimal extracellular collagen, and the intensity of CD34 expression was less than seen in solitary fibrous tumour. The final diagnosis was World Health Organization grade III hemangiopericytoma.

\section{Follow-UP}

At his two year follow-up clinic visit, the patient showed marked improved from his original presentation (Table). The MRI results showed no recurrence of the primary lesion (Figure $1 \mathrm{C}, \mathrm{D})$. Bone scan and abdominal $\mathrm{CT}$ results at two years show no evidence of metastasis.

\section{DisCUSSION}

The histological diagnosis of hemangiopericytoma (HPC) is controversial. It was initially considered a sub-category of meningioma, but the two entities harbour distinct phenotypes and chromosomal aberrations. More recently, the distinction between HPC and solitary fibrous tumor, a fibroblastic neoplasm occuring principally in the pleural cavity and which resembles 


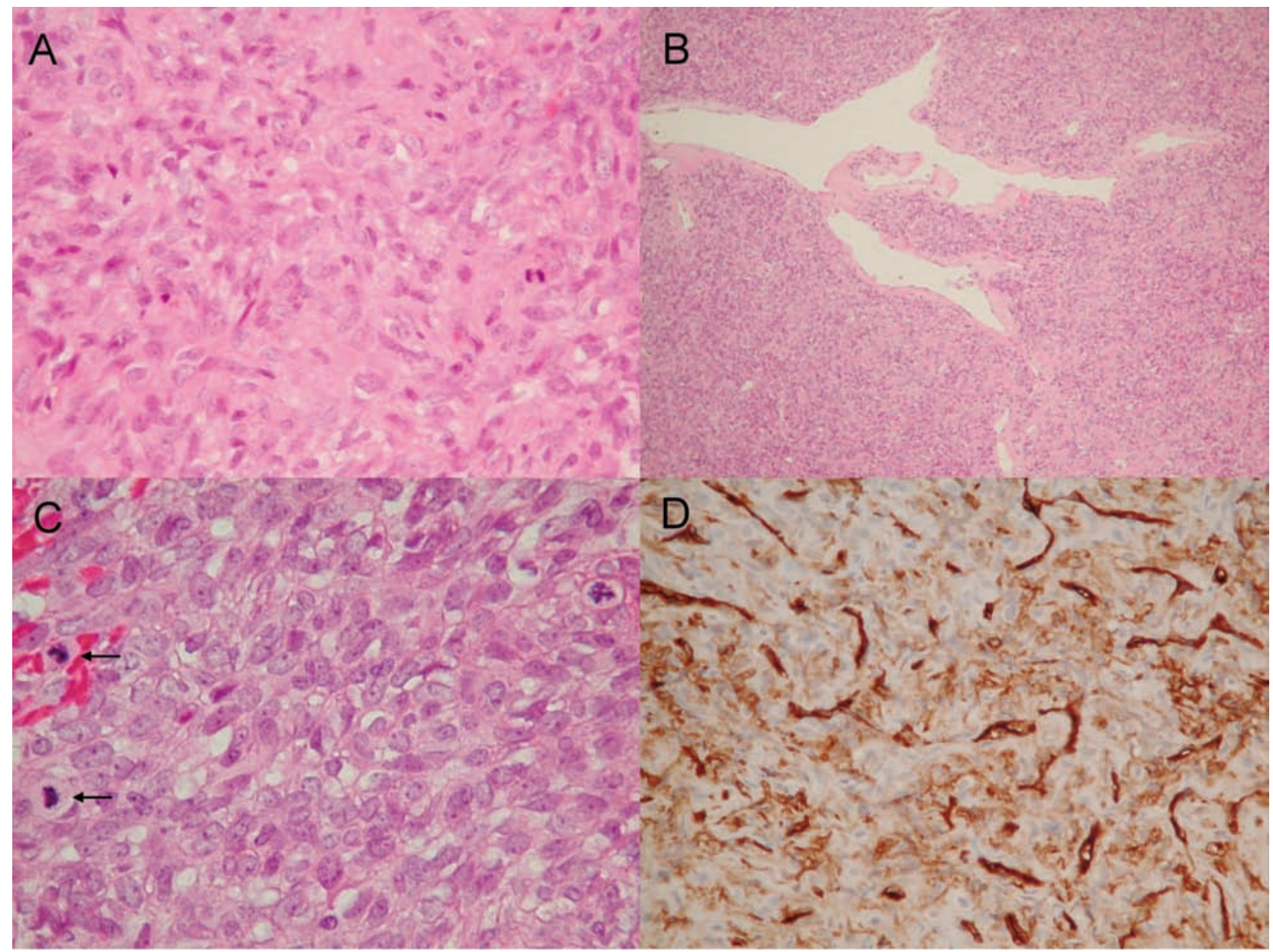

Figure 2: (A) Hematoxalin and eosin (HE) staining at high power. Individual cells show ill-defined borders with a moderate amount of eosinophilic cytoplasm. Nuclei are oval with speckled chromatin and occasional delicate nucleoli. (B) HE staining at low power. Staghorn shaped vessels are characteristic of this vascular tumor. (C) HE staining at high power. Mitoses are evident (see arrows) (D) Moderate positive CD 34 immunostaining of neoplastic cells with intense staining of capillaries.

hemangiopericytomas has been questioned. ${ }^{1-3}$ In this case the paucity of intercellular collagen, absence of a streaming pattern and modest intensity of CD34 immunostaining are indicative of HPC.

Devising an effective treatment strategy is essential for the management of this aggressive tumor. The best evidence available suggests that total resection is the most significant predictor of survival. ${ }^{9,11}$

Because of the aggressive nature of the tumor, adjuvant stereotactic radiosurgery was considered. Radiosurgery is often recommended when recurrence is less than $25 \mathrm{~mm}$ in the greatest diameter. Dufour et al reported the use of radiosurgery to treat recurrence in five patients that had not previously undergone radiotherapy. In two of the patients peripheral metastases occurred at 12 and 13 years of follow-up. In all five patients local control was obtained with the use of radiosurgery of the tumor and a $1 \mathrm{~cm}$ margin. ${ }^{13}$ Ecker et al performed radiosurgery on 15 patients with 45 lesions with an average volume of $7.8 \mathrm{~cm}^{3}$.
Radiosurgery destroyed 5 of the 45 tumors, reduced tumor size in ten cases and achieved local control in 27 cases. In total, $93 \%$ of the tumors were reduced in size, destroyed or controlled. ${ }^{10}$ The efficacy of this intervention remains questionable if there is no defined target, as in the patient we present. ${ }^{10,13}$

Since there was no recurrence visible, adjunctive radiotherapy was considered another option and some groups have demonstrated success with intracranial lesions..$^{10,11,13-16}$ While recurrence and metastases are reduced, overall mortality is unchanged. ${ }^{10,11,13}$ Radiotherapy is shown to reduce the risk of local recurrence in totally resected tumors; however, it was not shown to protect against neuraxis metastasis. ${ }^{10,13}$ In the study by Dufour et al patients were organized into two groups, Group 1 had eight patients that received radiotherapy (6000 rads) and Group 2 had nine patients that received no radiotherapy. The authors found a significant difference in the recurrence rates in Group 1 vs Group 2, $12 \%$ and $89 \%$ respectively $(\mathrm{p}=0.03)$. There was no difference in the occurrence of neuraxis metastasis or 
systemic metastasis. It should be noted however that these groups were not randomized. ${ }^{13}$ A study by Ecker et al had 19 of 38 patients undergo radiotherapy. Radiotherapy was not shown to have a significant reduction in recurrence. In this study there was also no randomization and criteria for offering radiotherapy were not uniformly applied. ${ }^{10}$

Chemotherapy was also considered but currently there is little evidence to support this treatment. Chemotherapy was shown to have no effect in one study, however the sample size was small and the study was observational rather than experimental. ${ }^{10}$ Current chemotherapy drugs show little benefit in patients with hemangiopericytoma.

The patient we present had a tumor that was not typical for an intracranial lesion and there is limited literature on the postoperative management of such a lesion. ${ }^{4,7}$ It is clear that these tumors are susceptible to radiation but it is unclear whether it is warranted in this case. Based on the literature reviewed it was decided that, at this time, the risks associated with radiotherapy outweighed the potential benefit. Our patient experienced marked clinical improvement during his two year follow-up and there was no evidence of metastatic disease at two years. Since HPC can recur after a prolonged disease-free interval, we plan to continue to follow him clinically and with serial imaging. ${ }^{9-11,13}$

Our recommendation based on the review of the literature is that the major goal of treatment should focus on total resection of the lesion. In the setting of sub-total resection adjuvant stereotactic radiosurgery is advisable. Stereotactic radiosurgery is also recommended in patients that display recurrence on follow-up imaging. There is no evidence to support the use of chemotherapy at this time, nor is there adequate support in the literature for fractionated radiotherapy in the context of total resection.

\section{REFERENCES}

1. Fletcher CD. The evolving classification of soft tissue tumours: an update based on the new WHO classification. Histopathology. 2006;48:3-12.

2. Gengler C, Guillou L. Solitary fibrous tumour and haemangiopericytoma: evolution of a concept. Histopathology. 2006;48: 63-74.

3. Koch M, Nielsen GP, Yoon SS. Malignant tumors of blood vessels: angiosarcomas, hemangioendotheliomas, and hemangioperictyomas. J Surg Oncol. 2008;97:321-9.

4. Kumar R, Vaid VK, Kumar V, Kalra SK. Hemangiopericytoma of thoracic spine: a rare bony tumor. Childs Nerv Syst. 2007;23: 1215-19.

5. Middleton LP, Duray PH, Merino MJ. The histological spectrum of hemangiopericytoma: application of immunohistochemical analysis including proliferative markers to facilitate diagnosis and predict prognosis. Hum Pathol. 1998;29:636-40.

6. Stout AP, Murray MR. Hemangiopericytoma: a vascular tumor featuring zimmermann's pericytes. Ann Surg. 1942;116:26-33.

7. Taniura S, Taniguchi M, Mizutani T, Takahashi H. Metastatic hemangiopericytoma to the cauda equina: a case report. Spine J. 2007;7:371-3.

8. Barba I, Moreno A, Martinez-Perez I, Tate AR, Cabanas ME, Baquero $\mathrm{M}$ et al. Magnetic resonance spectroscopy of brain hemangiopericytomas: high myoinositol concentrations and discrimination from meningiomas. J Neurosurg. 2001;94:55-60.

9. Chacko G, Chacko AG, Rajshekhar V, Muliyil JP. Intracranial hemangiopericytomas: correlation of topoisomerase IIalpha expression with biologic behavior. Surg Neurol. 2006;65:11-7.

10. Ecker RD, Marsh WR, Pollock BE, Kurtkaya-Yapicier O, McClelland R, Scheithauer BW, et al. Hemangiopericytoma in the central nervous system: treatment, pathological features, and long-term follow up in 38 patients. J Neurosurg. 2003;98: 1182-7.

11. Spitz FR, Bouvet M, Pisters PW, Pollock RE, Feig BW. Hemangiopericytoma: a 20-year single-institution experience. Ann Surg Oncol. 1998;5:350-5.

12. Fessler RG, Sekhar L. Atlas of neurosurgical techniques: spine and peripheral nerves. New York, USA. Thieme Medical Publishers inc. 2006.

13. Dufour H, Metellus P, Fuentes S, Murracciole X, Regis J, FigarellaBranger D, et al. Meningeal hemangiopericytoma: a retrospective study of 21 patients with special review of postoperative external radiotherapy. Neurosurgery. 2001;48:75662; discussion 762-3.

14. Mintz A, Perry J, Spithoff K, Chambers A, Laperriere N. Management of single brain metastasis: a practice guideline. Curr Oncol. 2007;14:131-43.

15. Patchell RA, Tibbs PA, Regine WF, Dempsey RJ, Mhiuddin M, Kryscio RJ, et al. Postoperative radiotherapy in the treatment of single metastases to the brain: a randomized trial. JAMA. 1998;280:1485-9.

16. Tsao MN, Lloyd NS, Wong RK, Rakovitch E, Chow E, Laperriere N. Radiotherapeutic management of brain metastases: a systematic review and meta-analysis. Cancer Treat Rev. 2005; $31: 256-73$. 